\title{
Covid-19 and the Impact on Energy Consumption: An Environmental Assessment of Ontario Canada.
}

\author{
Awomuti Adeboye ${ }^{*, * *}$, Bin Xu ${ }^{*, * *}$, Rodriguez torres Erik ${ }^{*, * *}$, Otonoku Tamara ${ }^{*, * *}$ \\ * Tongii University, UN Environment-Tongji Institute of Environment for Sustainable Development (IESD): College of Environmental Science and Engineering. \\ **State Key Laboratory of Pollution Control and Resource Reuse, College of Environmental Science and Engineering, Tongji University, Shanghai 200092, P.R. China. \\ DOI: 10.29322/IJSRP.10.08.2020.p104106 \\ http://dx.doi.org/10.29322/IJSRP.10.08.2020.p104106
}

\begin{abstract}
This study examines the impact of the Corona Virus Disease 2019 (COVID-19) pandemic on Energy Consumption in relation to Human and Environmental Responses in Ontario Canada. Supply and demand of Electricity which is a secondary form of energy was extensively studied and reviewed. This impact was compared between the active COVID-19 period in the study area and similar periods of previous years. The data sets studied, reviewed and analyzed were extracted from the database of the World Bank World Development Indicator and the Independent electricity System Operator (IESO) of Ontario Canada. From the study and analyses, it was evident that: COVID-19 has disrupted many businesses, resulting in reduced provincial demand/Consumption and creating significant uncertainty in supply and demand forecasts. Demand reductions in all hours ranging from $800-3,000 \mathrm{MW}$, which is $6-18 \%$ of typical demand for the similar periods/time of the year. Industrial and Commercial consumption were drastically reduced due to the closure of majority of the factories and industries as a result of the COVID-19 pandemic. This also led to the reduction in the Green House Gas and $\mathrm{Co} 2$ emissions in the studied period of active COVID-19, compared to similar periods of previous years. As expected, Residential and household demand experienced some increase because of the stay at home rule that was employed to manage social distancing concept for the COVID-19 period. An all-inclusive stakeholders dialogue is especially important during periods of uncertainty to ensure stable maintenance and reliable operation of the grid.
\end{abstract}

Key Words- Covid-19, Electricity Demand and Supply, Energy Consumption, Environmental Assessment, Residential Consumption,.

\section{INTRODUCTION}

Over the past few months, the Covid-19 pandemic has caused an extraordinary global economic and social crisis. The pandemic has significantly affected all aspects of life, including the energy sector[1-2].
Energy production and consumption remain the largest contributor of carbon dioxide emissions [3], as such, mitigation option requires measures that promote energy efficiency and the substitution of conventional energy sources with renewable energy technologies[4-5]. While the Sustainable Development Goal Seven seeks to ensure the availability and accessibility of clean and modern energy technologies [6], the underlying factors that propel energy consumption levels should not be underestimated. The energy sector has already felt the impact of Covid-19. The outbreak has contributed to a dampened demand for oil, resulting in plummeting prices and declining production, especially in the wake of the Russia-OPEC price war[2]. According to the IEA Oil Market Report - April 2020, global oil demand is expected to fall by a record $9.3 \mathrm{mb} / \mathrm{d}$ year-on-year in 2020[7]. Demand in April is estimated to be $29 \mathrm{mb} / \mathrm{d}$ lower than a year ago, down to a level last seen in 1995. Covid-19 has also accelerated the continued drop of gas prices[8].

A similar trend of falling demand and price reduction can be observed in the electricity sector. Europe has faced a record collapse in electricity prices[2]. In many European countries, power

prices have turned negative. This is evidenced by the data from Nord Pool (Europe's leading power market) and HUPX (Hungarian Power Exchange) regarding prices in the day-ahead market. Such a situation is considered normal in some countries during weekends or holidays, but now negative figures are also fixed on weekdays.

\section{Study Area}

Ontario is one of the thirteen provinces and territories of Canada[9]. Located in Central Canada, it is Canada's most populous province, with 38.3 percent of the country's population, and is the second-largest province in total area. Ontario is the fourth-largest jurisdiction in total area when the territories of the Northwest Territories and Nunavut are included[10]. It is home to the nation's capital city, Ottawa, and the nation's most populous city, Toronto, which is also Ontario's provincial capital. 
Ontario is bordered by the province of Manitoba to the west, Hudson Bay and James Bay to the north, and Quebec to the east and northeast, and to the south by the U.S. states of (from west to east) Minnesota, Michigan, Ohio, Pennsylvania, and New York.

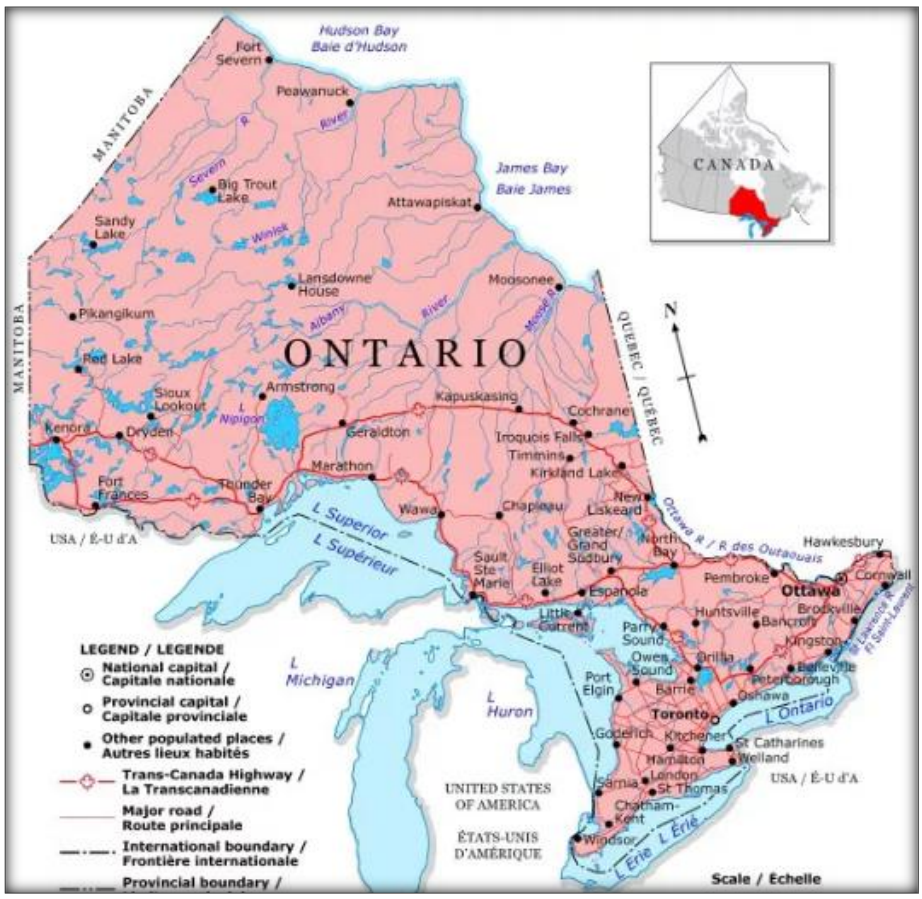

Figure 1:Map of Ontario showing cities and regions.

Almost all of Ontario's 2,700 km $(1,678 \mathrm{mi})$ border with the United States follows inland waterways: from the westerly Lake of the Woods, eastward along the major rivers and lakes of the Great Lakes/Saint Lawrence River drainage system. These include Rainy River, Pigeon River, Lake Superior, St. Mary's River, Lake Huron, St. Clair River, Lake St. Clair, Detroit River, Lake Erie, Niagara River, Lake Ontario and the St. Lawrence River from Kingston, to the Quebec boundary just east of Cornwall. There is only about $1 \mathrm{~km}(0.6 \mathrm{mi})$ of land border, made up of portages including Height of Land Portage on the Minnesota border[9].

Ontario is sometimes conceptually divided into two regions, Northern Ontario and Southern Ontario. The great majority of Ontario's population and arable land is in the south. In contrast, the larger, northern part of Ontario is sparsely populated with cold winters and heavy forestation. Each year, more than half of Canada's immigrants choose to settle in Ontario, the most populous and most centrally located of the country's provinces. A quarter of Ontario's nearly 13 million residents and almost half of the population of its provincial capital, Toronto, were born outside of Canada. Ontario is also the first stop for many of Canada's tourists, not only for its big city attractions, but also for the natural beauty found in its vast wilderness[10]. The Western Hemisphere's highest free-standing structure, the 1,815-foot CN Tower, soars high above the skyline of Toronto. Toronto is Ontario's provincial capital, Canada's most populous city, and one of the most multicultural communities on Earth. On clear days, visitors can see 75 miles away to another famous Ontario attraction, Niagara Falls, from the CN Tower's Sky Pod observation deck. Canada's national capital, Ottawa, lies 250 miles north of Toronto. Ottawa's Rideau Canal, one of Ontario's most popular boating sites in summer, freezes into the world's longest outdoor ice-skating rink once winter arrives[9].

\section{Co2 and Greenhouse Gas Emission}

The determination of factors affecting energy consumption and economic growth has been a topical subject of many studies, since the 1970s[11]. However, the existing evidence on the nexus between economic growth and energy consumption has been inconclusive[5]. Yet, an understanding of the determinants of energy consumption and its modeling in emerging economies is important. A detailed knowledge about energy consumption is becoming increasingly relevant, with the aim of saving costs, and reducing greenhouse gas emissions, because energy reduction is an environmental and economic challenge[12]. Between, energy consumption and economic growth have been found to be very complex due to prevailing factors, because energy is a key component of economic and social progress[13]. At the same time, the provision of energy often conflicts with sustainable development because energy production consumes resources and degrades the environment. Key trade-offs associated with energy consumption and its distribution arise from footprints on the environment, which is why an integrative, cross-sectoral approach to energy consumption is essential[12].

There is widespread agreement among energy economists and policy analysts in Canada and elsewhere that the ever-increasing energy demand is the major contributing factor to anthropogenic greenhouse gas emissions[2,5,11]. Energy is essential to all economic activities, however, the increasing attention given to global warming and climate change has renewed spur to research interest in the relationship between the environment, energy consumption, and economic growth. Nowadays, mitigation assessment of greenhouse gas emissions has become an integral part of the national and international climate policy agenda. However, to curb the greenhouse gas emissions and to ensure the sustainability of the economic development, it is important to better understand the link between greenhouse gas emissions, energy consumption, and economic growth[14]. In particular, increased energy consumption is frequently identified as a serious environmental impact. It is therefore extremely important to consider this impact because energy saving is intimately connected with countermeasures against global warming[15]. In fact, many evaluations have already been conducted on energy demand and consumption[16].

The remainder of the paper is organized as follows. The next section gives a brief review of the existing literature. Section 3 describes the data and methodology used in the study. The analyzed data are presented and discussed in Section 4. And section 5 concludes the paper.

\section{LITERATURE REVIEW}

The energy sector has already felt the impact of Covid-19[11]. The outbreak has contributed to a dampened demand for oil and conventional fossil fuel energy sources, resulting in reducing prices and declining production, especially in the wake of the Russia-OPEC price war. According to the IEA Oil Market 
Report - April 2020, global oil demand is expected to fall by a record $9.3 \mathrm{mb} / \mathrm{d}$ year-on-year in 2020. Demand in April is estimated to be $29 \mathrm{mb} / \mathrm{d}$ lower than a year ago, down to a level last seen in 1995[1,11]. Covid-19 has also accelerated the continued drop of gas prices.

A similar trend of falling demand and price reduction can be observed in the electricity sector [17]. Europe has faced a record collapse in electricity prices. In many European countries, power prices have turned negative. This is evidenced by the data from Nord Pool (Europe's leading power market) and HUPX (Hungarian Power Exchange) regarding prices in the day-ahead market. Such a situation is considered normal in some countries during weekends or holidays, but now negative figures are also fixed on weekdays.

Unsurprisingly, the strictness of confinement measures correlates with drops in consumption: $25 \%$ in Italy, $20 \%$ in France, $12 \%$ in the United Kingdom. Another concern is the impact of the reduced demand on utility companies' cash flows and the spillover effect this has on the energy sector[18]. Some of the other effects of COVID-19 on the Energy sector and Consumption are discussed below.

\section{Construction of New Energy Facilities and Infrastructure Delayed or Stopped}

Many companies across different sectors globally have ceased or decreased capital expenditures where possible, and the energy sector is no exception[11]. For example, Distribution System Operators (DSOs) are delaying most initiated projects, resulting in a substantial decrease in the procurement of goods and services[19]. Non-critical investments have been suspended. The fulfillment of investment programs by Transmission System Operators (TSOs) and DSOs is also at risk.

Covid-19 is having an especially negative impact on the renewables sector. One of the main problems relates to the delivery of equipment to power plants. China, which is among the countries most heavily affected by the coronavirus, is the main global producer of many clean energy technologies, such as solar panels, wind turbines and batteries[20-21]. Since coronavirus has delayed deliveries from China, renewable energy companies are not able to comply with deadlines for equipment installation. For instance, in India alone 3,000 MW of solar and wind energy projects face delays, due to the coronavirus lockdown[22]. BYD, the world's leading producer of rechargeable batteries, was unable to complete tests of new models of rechargeable batteries due to the pandemic, and this has led to a reduction in delivery volumes of rechargeable batteries for the European market [23].

\section{Default of Payment}

In many countries (including all but two Contracting Parties of the Energy Community), customers have been advised by energy regulators and governments to delay the payment of utility bills. Defaults on payments cause cascade effect and impact the whole sector[11]. Although there is widespread tolerance of nonpayment by end-users, policymakers did not explicitly define if leniency towards non-payment would be applied further along the supply chain (to DSOs, TSOs, suppliers and producers). So far, none of the Contracting Parties of the Energy Community have explicitly defined who will bear the costs of financing this debt[18].

The waiving of interest and bans on disconnection will most likely increase costs for DSOs. Consequently, their revenues will be decreased and, if the crisis continues, their financial status will deteriorate. It is inevitable that all this would negatively impact the cash flow and short-term liquidity of DSOs. A lack of working capital to finance short-term liabilities for regular operation is expected within two to three months if the situation persists[2,11].

\section{Response of Policymakers, Regulators, and Market Participants}

Countries around the world are taking steps to support the energy sector and to mitigate the negative effects of the crisis[11]. There are myriad challenges that policy makers, regulators, TSOs and DSOs need to address to ensure energy security.

Europe's energy regulators have already taken special measures to ensure a safe and reliable energy supply by guaranteeing essential services such as gas, heating and power, as well as measures aimed to ease financial requirements on consumers who face economic difficulties during lock down (bill-paying measures for vulnerable consumers to avoid disconnections)[24].

In some countries, certain measures have also been taken to support the renewables sector. For instance, Poland's government has developed a draft of the so-called Anti-Crisis Shield Act, which provides the President of the Energy Regulatory Authority with the right to extend deadlines for renewable energy producers for commencement of sales within the auction system[25].

DSOs have implemented a number of organizational measures related to the safety of personnel, ensuring maintenance activities, securing supplies, etc. The security and safety of dispatch centers is ensured by means of: isolated teams in dispatch centers with back-up teams in isolation on stand-by; restricted access to dispatch centers and to stand-by units; and standby teams composed of retired staff, in order to maintain the safety and prevent the exhaustion of key staff, and address the issue of the lack of qualified and trained key staff[26].

Regular maintenance activities and field work are restricted to a minimum, with repair and restoration being prioritized. Planned interruptions for regular maintenance are either suspended, postponed, or implemented with a limited duration. Mobile intervention teams have been established as a back-up for field units. The quality of service, however, may be at risk if planned repairs and maintenance works are postponed for too long. According to the document summarizing issues of concern based on ongoing discussions held on April 21, 2020, DSOs reported that current supplies of vital spare parts, tools and equipment are sufficient for repairs and urgent remedial maintenance; some 
DSOs have a central warehouse or a centrally managed stock system, enabling more efficient use of available vital spare parts, materials, tools and equipment. Nevertheless, should the crisis continue, there is a risk to network and staff safety if supplies are not replenished in time[18].

As was rightly pointed by the International Energy Agency, the sharp decline of the oil market may put clean energy transitions at risk by reducing the impetus for energy efficiency policies [2729]. Without measures by governments, cheaper energy always leads consumers to use it less efficiently. It reduces the appeal of buying more efficient cars or retrofitting buildings to save energy. Thus, policymakers should keep the "green" agenda in mind.

Covid-19 has drastically impacted energy sector across the globe. The whole range of consequences for the energy sector is yet to be revealed and is difficult to predict, however it is already clear that demand for energy resources has dropped, prices have plummeted and non-payment of utilities bills by end-consumers will have a detrimental effect along the supply chain (DSOs, TSOs, suppliers and producers)[11]. Notwithstanding, the "green" agenda should not slip away from the list of national policymakers' and regulators' priorities. Although there are numerous empirical studies that have contributed to the discussion and understanding on energy-growth nexus. Yet, there appears to be no consensus concerning the direction of causality between energy consumption and economic growth[30$31]$.

The general observation that emerges from various existing literature is that most studies on the energy-environment-growth dynamics have employed aggregated level data that led to conflicting results[5]. As pointed out, disaggregate level data may provide further insight regarding the link between output growth, energy consumption and environmental degradation. Thus, we feel the usage of disaggregated data may elicit the correct diagnosis of energy environment growth nexus[31-33]. Energy has a crucial role to play in a global development context. The potential for energy to improve living standards, whether through the freeing of time from household chores (for example, washing clothes or cooking); increased productivity; improved healthcare and education services; or digital connections to local, regional and global networks can never be overemphasized[34].

The link between energy consumption and economic growth has been a topic of wide discussion. A large number of studies have attempted to derive the causal relationship between energy consumption and economic growth, however no clear consensus has emerged[35]. This can be partly attributed to the fact that the link between energy and prosperity is not always unidirectional. Gaining access to electricity and other energy sources may provide an initial increase in GDP, but having higher GDP may in turn drive higher energy consumption. Additionally, progress in development outcomes can be complex: a number of parameters may be improving at the same time. If, for example, energy access and consumption, nutrition, education, health, and sanitation are all improving simultaneously (and having complex relationships with one another), it can be hard to directly attribute improvement in living standards back to a single parameter[5].

Home electricity use is up in Ontario and Quebec since the start of the pandemic even as overall consumption rates have gone down, according to hydro utilities in the two provinces[18]. According to Hydro-Québec, the province's residential electricity consumption between March and July 2020 was 4.27 per cent higher than during the same time last year. In Ontario, meanwhile, the Independent Electricity System Operator said consumption increased by 15 per cent. Despite the overall provincial increases, certain regions reported differences in residential usage: Hydro Ottawa, for example, said via email that residential electricity consumption in Canada's capital increased by approximately four per cent.

In contrast, residents of Quebec's Outaouais region increased their consumption by seven per cent[2]. The numbers aren't surprising because the region's largest industry is government services. governments have closed completely, So the government employees continue to work from home. This leads to a much higher use of computer equipment at home. Despite the rise in residential electricity use between mid-March and the end of July, energy companies say they're seeing consumption go down overall. In Quebec, consumption across all sectors decreased by 5.04 per cent compared to the same period last year. Ontario saw usage plummet between 10 per cent and 12 per cent. The overall decrease is mainly due to stagnation brought on by shuttered or slowed economies, and that translates into energy companies bringing in less income from their commercial and industrial customers. Less income means less profit, and Less profit means less dividends paid to the shareholder and, in this case, the shareholder is the government.

The effects of social distancing guidelines are likely to continue affecting electricity consumption during the next few months[2]. It is expected that retail sales of electricity in the commercial sector will fall by $6.5 \%$ in 2020 because many businesses have closed and many people are working from home. Similarly, industrial retail sales of electricity are projected to fall by $6.5 \%$ in 2020 as many factories cut back production. Total U.S. electric power sector generation is projected to decline by 5\% in 2020 . Most of the expected decline in electricity supply is reflected in lower fossil fuel generation, especially at coal-fired power plants. After decreasing by $2.8 \%$ in 2019 , EIA forecasts that U.S. energy-related carbon dioxide (CO2) emissions will decrease by $11 \%$ in 2020 . This record decline is the result of restrictions on business and travel activity and slowing economic growth related to COVID-19.

\section{Huge Emissions Reductions}

Carbon dioxide emissions are down across the globe, most significantly in places where industries are shuttering $[9,36]$. The Centre for Research on Energy and Clean Air reported the lockdown in China cut the country's carbon emissions by 25 per cent, or 200 megatons of $\mathrm{CO} 2$, because of a reduction in things like coal burning, oil refining and airline traffic[36]. Though it is not certain if these declines will be permanent, as those same activities will be back online once the pandemic passes. 
Much of that production will ramp back up double time. So, the net emission reduction will not be known until well after the fact. And it's likely to not be nearly as big as what we're seeing right now.

Emission reductions from personal choices are less significant. However, there are still lessons to be learned, including the importance of pushing industry toward clean energy sources.

It has been said that climate change is affecting influenza in general. And of course, this is a form of influenza, it's making our seasons longer, which gives the viruses more time to mutate. As climate changes too, in a warmer world, there's some indication that our immune system might become less robust so we're more likely to get it. Studies from during the SARS outbreak in 2003 that showed air pollution made people more vulnerable to viruses. It was found that people who lived in polluted areas who were infected were twice as likely to die from it as people who lived in areas that were not polluted, So our actions have consequences and what this is highlighting is that our choices matter in every aspect of our lives[37-39].

However, climate change isn't solely to blame for this pandemic. Diseases spread by vectors such as ticks, and mosquitoes do get worse because climate change increases their range northward. COVID-19, however, is spread by humans, and our range isn't limited by climate. Measures taken to fight the COVID-19 pandemic have cut worldwide greenhouse gas emissions by 17 per cent, says newly published research[40]. Behavior change on its own can only do so much, You really need to have structural change.

Figures for emissions of greenhouse gases aren't normally available until after emitters have reported them. In this case, researchers used a variety of proxies to estimate releases of carbon dioxide and other climate-change-causing gases as countries brought in stiff measures to restrict individual movement and activity. Tech companies such as Apple provided data. The aviation industry offered flight information. Electric utilities gave figures on generation and consumption[2].

\section{Electricity Consumption and Demand}

In the last week of March, electricity consumption in Ontario was the lowest in 15 years according to eMerge, a local nonprofit that promotes renewable energy to reduce the effects of climate change[18].

The organization is projecting a continued decline as the lockdown remains in place during the COVID-19 pandemic.

"We seem to be settling into a new normal, and that new normal is significantly lower consumption," said executive director of eMerge, Evan Ferrari. Every day, we review data from The Independent Electricity System Operation (IESO), which includes residential and commercial energy usage in Ontario including bio fuel, solar, wind, gas, hydro and nuclear. We collect the data and organize it into a chart that compares levels from 2005-2020 and takes into account variables like changing weather, holidays and peak times. Ferrari has noticed a steep decline in provincial consumption levels since March 22 - the day before Premier Doug Ford announced the provincial lockdown.

Socioeconomics are not that different from the average in Ontario, so we suspect that our curves are looking pretty similar, he said, adding that local information isn't readily available online but that eMerge will continue to update their blog regularly with relevant information.

Similar patterns have emerged across the country and around the world as the mandatory closure of non-essential businesses and industries has forced many people to stay at home and practice physical distancing. Hydro-Quebec says residential consumption is up two per cent and commercial consumption is down three per cent. In British Columbia, the province's hydro provider reported business and residential consumption dropped by 15 and 13 per cent respectively.

The drop in demand is also reflected in lower prices. On March 24, HydroOne announced that it would temporarily reduce pricing to an off-peak flat rate for 45 days. Ferrari says that while this is a welcome financial relief for many people currently out of work, he still recommends reducing energy-intensive activities during peak hours. If everyone is doing their laundry, dishwashing, and cooking at exactly the same time ... our CO2 emissions go through the roof. From a climate change perspective, we call it peak shaving. If we can shift the use of electricity away from that peak, we reduce the fossil fuel that's burned[18].’

Ferrari believes eMerge has an important role to play in ensuring climate change is part of the conversation surrounding COVID19. The organization hosts public programs to promote energyefficient practices as well as home visits to advise on ways to reduce energy consumption, but Ferrari says they are making the switch to virtual home visits and phone consultations.

"We're hoping we can provide people with other opportunities to save money at this time by reducing energy in different ways and reducing their impacts on climate change." Looking ahead, Ferrari says he's cautiously optimistic that the COVID-19 pandemic could mean a shift towards a more energy efficient world. COVID-19 demands a massive international approach and many countries in the world are profoundly impacted by it. The biggest impact envisaged is that people will take that same vigor and approach fighting climate change[20,41-42]. 


\section{Methodology}

To conduct an assessment of energy consumption in Ontario Canada, this study employs data from the database of the World Bank World Development Indicator and the Independent electricity System Operator (IESO) of Ontario Canada. data variables that are used Include; GHG and $\mathrm{Co} 2$ emission rates, Energy consumption, Electricity demand, supply and consumption, Industrial Electricity consumption, commercial Electricity consumption, Residential and household Electricity consumption, Daily Energy use, Peak demand hours, Overnight lows. among others.

The Data were intensely analyzed and discussed, and conclusions inferred.

\section{RESUlts AND Discussions}

This section is based on findings derived from data obtained from the World Bank World Development Indicator and the Independent electricity System Operator (IESO) of Ontario Canada.

It was evident that there was a significant reduction in Electricity demand in all hours ranging from $800-3,000 \mathrm{MW}$, which is 6 $18 \%$ of typical demand for this time/period of year.

Peak period demand was reduced by approximately $10-15 \%$. The overall energy consumption to date continues to be approximately $10-12 \%$ lower than normal while Demand is expected to continue to decrease through April and May when warmer weather materializes.

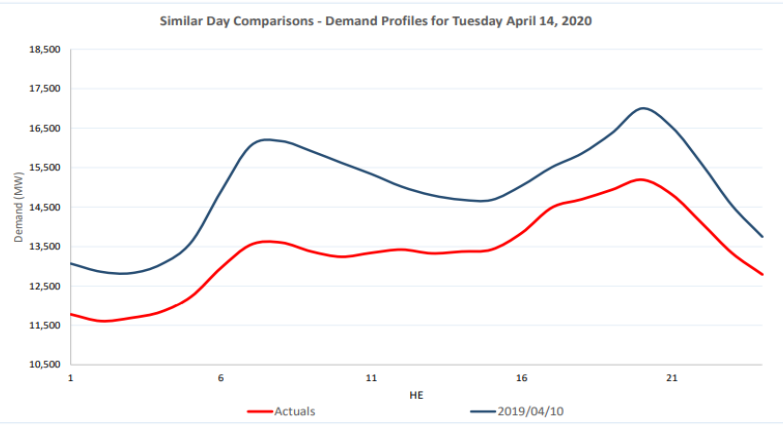

Figure 2:Demand for energy during the the COVID-19

From Figure 2 above, it was clearly evident that there was a significant and visible difference between the demand for energy during the the COVID-19 period, and the demand for energy a year ago in the same period of time. This shows a definite impact of COVID-19 on demand for Energy.

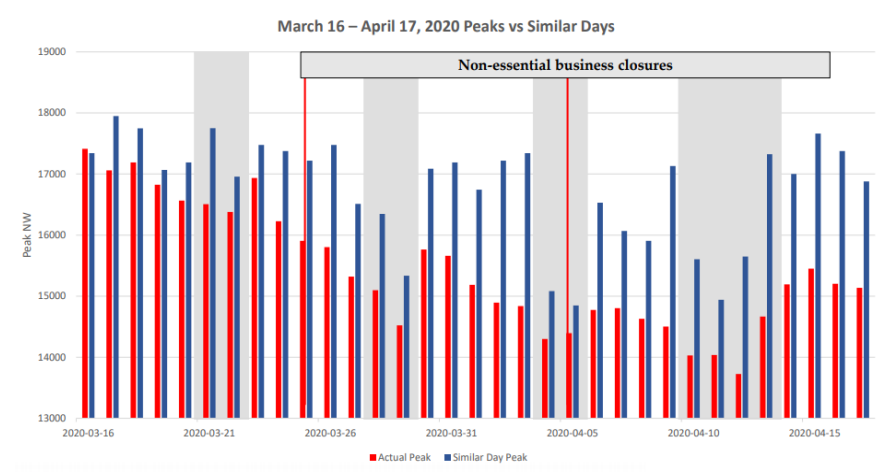

Figure 3:Peak demand on an electrical grid

A peak demand on an electrical grid is the highest electrical power demand that has occurred over a specified time period. It could be calculated annually, daily or seasonally. In Figure 3, the peak demand during COVID-19 period was compared with similar days, and the data obtained shows that Peak Demand was down by $10-15 \%$. This further reiterates that COVID-19 has some impact on energy consumption.

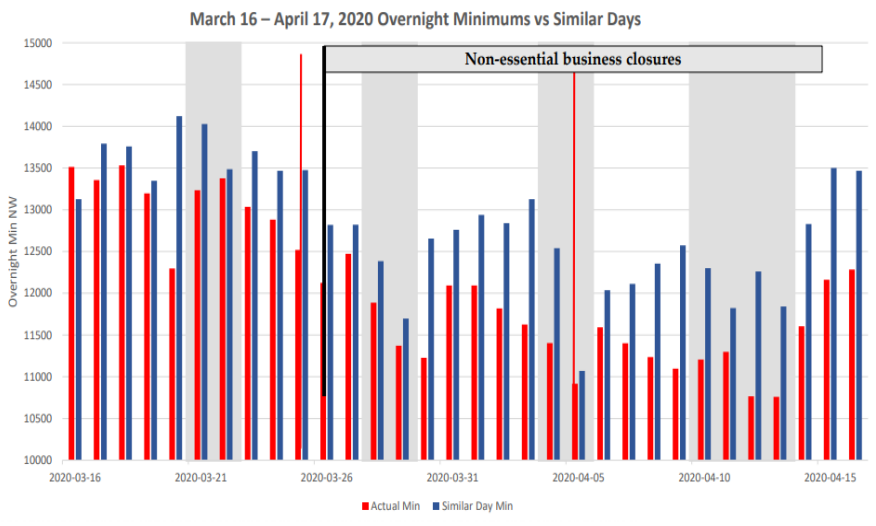

Figure 4:Overnight lows of electricity consumption

Another impact of COVID-19 on power consumption is found in the comparism of the Overnight lows of Electricity consumption during the active period of COVID-19 versus similar day in same period of the year as depicted in Figure 4, the Overnight lows came down to between $9-13 \%$.

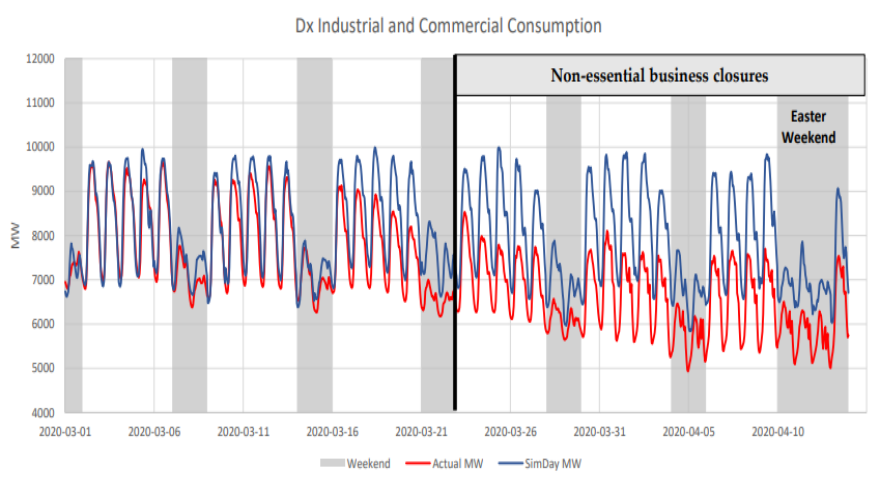

Figure 5:Industrial/Commercial energy consumption 
Figure 5 shows in clear terms plummeting Industrial and Commercial consumption compared against similar days, this was more evident after the closure of the non-essential businesses as a measure to control the spread of COVID-19.

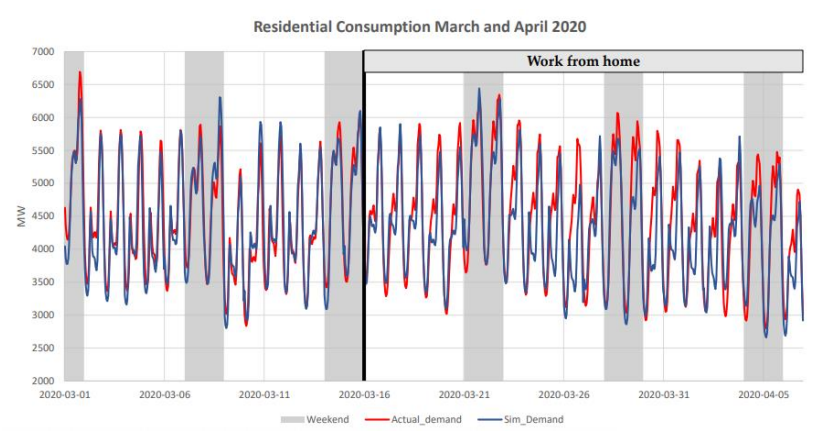

Figure 6:Residential consumption

On the contrary, residential consumption recorded some increase when compared to similar days. This is as a result of the stay at home and the social distancing policies being implemented across the entire province of Ontario. The data in figure $\mathbf{6}$ is clear about this. It also shows that there is a clear relationship between staying at home, and residential electricity demand and consumption.

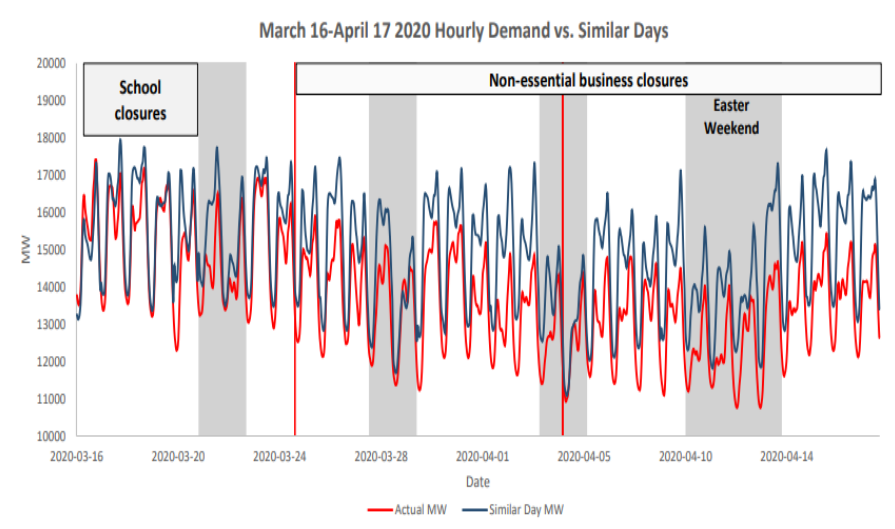

Figure 7:Overall electricity demand

Overall electricity demand in Ontario is being considered in Figure 7, data collected across all sectors of the economy shows an overall decrease in demand for energy and because of the closure of most industries and factories except essential service providers. This singular act has greatly affected overall Electricity demand and consumption in Ontario.

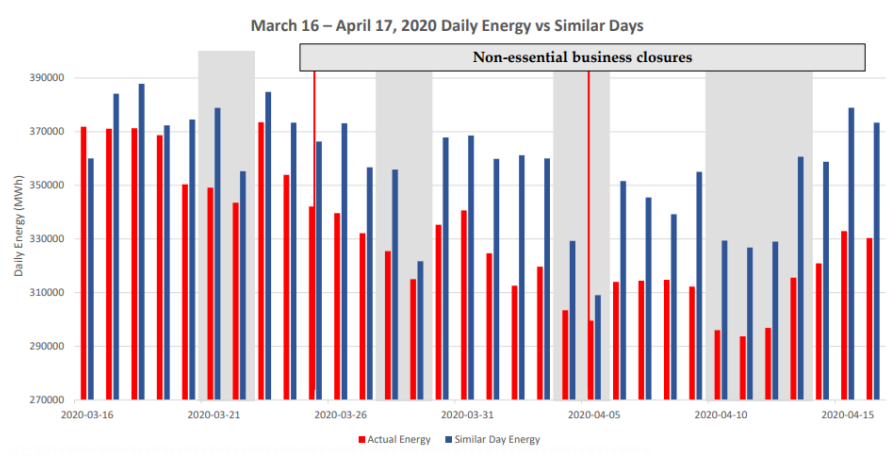

Figure 8:Ontario's energy use

As compared to similar days in previous years, in Figure 8, Ontario's energy use was seen to decrease between $10-12 \%$. This further shows the impact of COVID-19 on energy use as compared to similar days.

\section{CONCLUSION}

As observed, Ontario's electricity system is reliable, with enough supply available to meet demand under a variety of risk scenarios, however the IESO and stakeholders have been limiting staff on-site, deferring non-essential work, and focusing on core operations for the special period.

Dialogue between and amongst stakeholders is especially important during periods of uncertainty to ensure optimal operational maintenance.

From the analyses and comparison of data from previous and present year, High surplus baseload generation $(\mathrm{SBG})$ conditions are often observed in the spring when demand is low and there are large amounts of energy from hydroelectric resources caused by higher water levels

The IESO continues to update its assessment of SBG conditions and SBG management options through spring/early summer. 


\section{REFERENCES}

[1] I. R. E. Agency, "IRENA's Global Renewables Outlook: Energy transformation 2050.," Journal of International Renewable Energy Agency, 2020

[2] Forbes.com. "Short Term Energy Outlook Shows Impact of Covid 19 on Energy Sector." https://www.forbes.com.

https://www.forbes.com/sites/rrapier/2020/05/17/shortterm-energy-outlook-shows-impact-of-covid-19-onenergy-sector/\#69eaf4e045ed (accessed 06-05-2020, 2020).

[3] I. A. Mensah et al., "Investigation on key contributors of energy consumption in dynamic heterogeneous panel data (DHPD) model for African countries: fresh evidence from dynamic common correlated effect (DCCE) approach," (in English), Environ Sci Pollut R, Jul 62020

[4] H. Zhou, S. J. Qu, Z. Wu, and Y. Ji, "A study of environmental regulation, technological innovation, and energy consumption in China based on spatial econometric models and panel threshold models," (in English), Environ Sci Pollut R, Jul 22020

[5] S. A. Sarkodie, A. O. Crentsil, and P. A. Owusu, "Does energy consumption follow asymmetric behavior ? An assessment of Ghana's energy sector dynamics," (in English), Sci Total Environ, vol. 651, pp. 2886-2898, Feb 152019

[6] G. Dileep and S. N. Singh, "Maximum power point tracking of solar photovoltaic system using modified perturbation and observation method," (in English), Renew Sust Energ Rev, vol. 50, pp. 109-129, Oct 2015

[7] F. Ecer, D. Pamucar, S. H. Zolfani, and M. K. Eshkalag, "Sustainability assessment of OPEC countries: Application of a multiple attribute decision making tool," (in English), J Clean Prod, vol. 241, Dec 202019

[8] U. Uzar, "Political economy of renewable energy: Does institutional quality make a difference in renewable energy consumption?," (in English), Renew Energ, vol. 155, pp. 591-603, Aug 2020

[9] Wikipedia. "The Province of Ontario " Wikipedia. https://en.wikipedia.org/wiki/Ontario (accessed 13-072020, 2020).

[10] E. Canada. "Travel Guides in Canada/ontario." Eplore Canada. https://www.iexplore.com/articles/travelguides/north-america/canada/ontario/weather (accessed 18-07-2020, 2020).

[11] PV-Magazine.com. "Impact of Covid 19 on the Global Energy Sector." PV-Magazine.com. https://www.pvmagazine.com/2020/04/24/impact-of-covid-19-on-theglobal-energy-sector/ (accessed 2020).

[12] X. W. Zhang, T. B. Yu, Y. X. Dai, S. Qu, and J. Zhao, "Energy consumption considering tool wear and optimization of cutting parameters in micro milling process," (in English), Int J Mech Sci, vol. 178, Jul 15 2020

[13] T. Wang, G. S. He, J. Guo, Y. Yin, and L. L. Li, "Energy consumption and economic growth in China's marine economic zones-an estimation based on partial linear model," (in English), Energy, vol. 205, Aug 15 2020

[14] V. Paramesh, V. Arunachalam, A. Nikkhah, B. Das, and S. Ghnimi, "Optimization of energy consumption and environmental impacts of arecanut production through coupled data envelopment analysis and life cycle assessment," (in English), J Clean Prod, vol. 203, pp. 674-684, Dec 12018

[15] J. Y. Li, C. L. Zhang, and J. L. Tian, "Research on China's Economic Growth and the Consumption of Energy in the Low-Carbon Economy," (in English), Adv Mater Res-Switz, vol. 361-363, pp. 1897-1900, 2012

[16] B. Y. Yu, X. J. Yang, Q. Y. Zhao, and J. X. Tan, "Causal Effect of Time-Use Behavior on Residential Energy Consumption in China," (in English), Ecol Econ, vol. 175, Sep 2020

[17] G. K. F. Tso and J. J. Guan, "A multilevel regression approach to understand effects of environment indicators and household features on residential energy consumption," (in English), Energy, vol. 66, pp. 722731, Mar 12014

[18] Emerge. "Will Covid-19 Lead to a New Normal in Energy Consumption?" Emerge. https://www.guelphtoday.com/grounded/will-covid-19lead-to-a-new-normal-in-energy-consumption-2221436 (accessed 16th July 2020, 2020).

[19] D. S. Operators, " Response to Covid-19 Crisis: Actions Taken and Concerns Expressed of 21 April 2020.," Journal of Energy Distribution Systems, 2020

[20] E. C. Secretariat, " Report "COVID-19: Security of energy supply monitoring" of 01 April 2020.," Journal of Energy Community Secretariat, 2020

[21] K. D. Kanniah, N. A. F. K. Zaman, D. G. Kaskaoutis, and M. T. Latif, "COVID-19's impact on the atmospheric environment in the Southeast Asia region," (in English), Sci Total Environ, vol. 736, Sep 202020

[22] O. A. Ataguba and J. E. Ataguba, "Social determinants of health: the role of effective communication in the COVID-19 pandemic in developing countries," (in English), Global Health Action, vol. 13, no. 1, Dec 31 2020

[23] F. F. Martins and H. Castro, "Raw material depletion and scenario assessment in European Union - A circular economy approach," (in English), Energy Rep, vol. 6, pp. 417-422, Feb 2020

[24] C. o. E. E. R. (CEER), "Keeping the lights on saves lives - Energy sector and regulators guarantee energy supply during lockdown," Journal of Council of European Energy Regulators (CEER), 2020

[25] O. Usman, A. A. Alola, and S. A. Sarkodie, "Assessment of the role of renewable energy consumption and trade policy on environmental degradation using innovation accounting: Evidence from the US," (in English), Renew Energ, vol. 150, pp. 266-277, May 2020

[26] L. Cong, G. H. Guo, M. Yu, F. Yang, and L. Tan, "The energy consumption and emission of polyurethane pavement construction based on life cycle assessment," (in English), J Clean Prod, vol. 256, May 202020 
[27] S. Thapar, "Energy consumption behavior: A data-based analysis of urban Indian households," (in English), Energ Policy, vol. 143, Aug 2020

[28] H. X. H. Bao and S. H. Li, "Housing wealth and residential energy consumption," (in English), Energ Policy, vol. 143, Aug 2020

[29] M. Aksoezen, M. Daniel, U. Hassler, and N. Kohler, "Building age as an indicator for energy consumption," (in English), Energ Buildings, vol. 87, pp. 74-86, Jan 1 2015

[30] I. M. H. Yeung and W. S. W. Chung, "Trends in Energy Consumption and Carbon Dioxide Emissions of Private Cars and Buses in Hong Kong," (in English), Transportation \& Logistics Management, pp. 703-710, 2012

[31] A. Yumashev, B. Slusarczyk, S. Kondrashev, and A. Mikhaylov, "Global Indicators of Sustainable Development: Evaluation of the Influence of the Human Development Index on Consumption and Quality of Energy," (in English), Energies, vol. 13, no. 11, Jun 2020

[32] S. M. Ziaei, "Effects of financial development indicators on energy consumption and $\mathrm{CO} 2$ emission of European, East Asian and Oceania countries," (in English), Renew Sust Energ Rev, vol. 42, pp. 752-759, Feb 2015

[33] I. K. Maji, C. Sulaiman, and A. S. Abdul-Rahim, "Renewable energy consumption and economic growth nexus: A fresh evidence from West Africa," (in English), Energy Rep, vol. 5, pp. 384-392, Nov 2019

[34] G. Wood and M. Newborough, "Dynamic energyconsumption indicators for domestic appliances: environment, behaviour and design," (in English), Energ Buildings, vol. 35, no. 8, pp. 821-841, Sep 2003

[35] X. H. Zhang et al., "Several novel indicators being applied to analyze the relationships between Chinese economic growth, energy consumption and its impact of emissions," (in English), Ecol Indic, vol. 15, no. 1, pp. 52-62, Apr 2012

[36] C. B. Coporation. "Covid-19 has led to Huge Emissions Reductions can we Learn from this?" Canadian Broadcasting Coporation

https://www.cbc.ca/radio/quirks/mar-21-covid-19-vulnerabilitycovid-and-climate-and-more-1.5504342/covid-19-hasled-to-huge-emissions-reductions-can-we-learn-fromthis-1.5504346 (accessed 14th July, 2020).

[37] H. Sung et al., "COVID-19 Molecular Testing in Korea: Practical Essentials and Answers From Experts Based on Experiences of Emergency Use Authorization Assays," (in English), Ann Lab Med, vol. 40, no. 6, pp. 439-447, Nov 2020

[38] M. Niazkar and H. R. Niazkar, "COVID-19 Outbreak: Application of Multi-gene Genetic Programming to Country-based Prediction Models," (in English), Electron J Gen Med, vol. 17, no. 5, Oct 2020

[39] A. G. Hadi, M. Kadhom, N. Hairunisa, E. Yousif, and S. A. Mohammed, "A Review on COVID-19: Origin,
Spread, Symptoms, Treatment, and Prevention," (in English), Biointerface Res App, vol. 10, no. 6, pp. 72347242, Dec 152020

[40] C. N. Post. "Covid-19 Measures Cut World Greenhouse Gas Emissions by Nearly a fifth." https://nationalpost.com/pmn/news-pmn/canada-news$\mathrm{pmn} /$ covid-measures-cut-world-greenhouse-gasemissions-by-nearly-a-fifth-study (accessed 19th June 2020

2020).

[41] A. Rahman and N. J. Sathi, "Knowledge, Attitude, and Preventive Practices toward COVID-19 among Bangladeshi Internet Users," (in English), Electron J Gen Med, vol. 17, no. 5, Oct 2020

[42] M. Monajjemi, S. Shahriari, and F. Mollaamin, "Evaluation of Coronavirus Families \& Covid-19 Proteins: Molecular Modeling Study," (in English), Biointerface Res App, vol. 10, no. 5, pp. 6039-6057, Oct 152020

\section{AUTHORS}

First Author - Awomuti Adeboye, Master candidate, Tongji University, UN Environment-Tongji Institute of Environment for Sustainable Development (IESD): College of Environmental Science and Engineering; Email: boyesky@yahoo.com; Phone No +86 18521358350/+234 8037887139; Address: 1239 Siping Road, Shanghai 200092, China.

Second Author - Xu Bin, Mentor and Supervisor, Tongji University, UN Environment-Tongji Institute of Environment for Sustainable Development (IESD): College of Environmental Science and Engineering: Email: binxu@tongji.edu.cn, Phone No: +86 13916186347/+86-21-65981831 ext.8016, Address: 1239 Siping Road, Shanghai 200092, China.

Third Author - Rodriguez torres Erik, Master candidate, Tongji University, UN Environment-Tongji Institute of Environment for Sustainable Development (IESD): College of Environmental Science and Engineering, Email: exoerik_337@hotmail.com, Phone No: +86 19821228687, Address: 1239 Siping Road, Shanghai 200092, China

Fourth Author - Otonoku Tamara, Master candidate, Tongji University, UN Environment-Tongji Institute of Environment for Sustainable Development (IESD): College of Environmental Science and Engineering, Email: otonokutamara92@gmail.com, Phone No: +86 19821813117, Address: 1239 Siping Road, Shanghai 200092, China

Corresponding Author - Xu Bin, Mentor and Supervisor, Tongji University, UN Environment-Tongji Institute of Environment for Sustainable Development (IESD): College of Environmental Science and Engineering: Email: binxu@tongji.edu.cn, Phone No: +86 13916186347/+86-2165981831 ext.8016, Address: 1239 Siping Road, Shanghai 200092, China. 